\title{
ComplaANCE E RESPONSABILIDADE DE PESSOAS JURÍDICAS
}

\section{COMPLIANCE AND RESPONSIBILITY OF LEGAL ENTITIES}

\author{
Ricardo Marcondes Martins \\ Doutor em Direito Administrativo pela PUC-SP. Professor de Direito Administrativo da PUC-SP. \\ ORCID: [orcid.org/0000-0002-4161-9390]. \\ ricmarconde@uol.com.br \\ Recebido em: 15.12 .2020 \\ Aprovado em: 17.02 .2021 \\ DOI: [https://doi.org/10.48143/rdai/17.rmm]
}

\section{Áreas do DiretTo: Penal; Civil}

Resumo: Este estudo tem por objeto a relação conceitual entre o compliance e a responsabilidade das pessoas jurídicas por atos de corrupção. Em relação às pessoas jurídicas, há uma dupla imputação: a vontade da pessoa fisica é imputada ao órgão; e a vontade deste, nos termos da lei e dos atos constitutivos, é imputada à pessoa jurídica. A responsabilidade subjetiva da pessoa jurídica exige a prática de um ato típico, antijurídico, culpável e punivel por uma pessoa física vinculada a ela e que essa atuação seja chancelada pelo órgão deliberativo. A responsabilidade administrativa, ao contrário da penal, admite a dissociação entre o autor e o responsável; por isso, aceita a responsabilização objetiva. Assim, dispensa a chancela do órgão competente. $A$ adoção de mecanismos de compliance gera a diminuição, e não a exclusão, da responsabilidade: é um importante fator a ser considerado na dosimetria da sanção administrativa.

Palavras-chave: Responsabilidade da pessoa jurídica - Responsabilidade objetiva - Dupla imputação - Compliance - Vontade.
ABSTRACT: This study has as its object the conceptual relationship between compliance and the liability of legal entities for acts of corruption. In relation to legal entities, there is a double imputation: the will of the individual is imputed to the public agency; and it's will, under the terms of law and the constitutive acts, is imputed to the legal entity. The subjective responsibility of the legal entity requires the practice of a typical, anti-legal, culpable and punishable act by an individual linked to the legal entity, and that this action is approved by the deliberative body. Administrative responsibility, unlike criminal responsibility, allows the dissociation between the author and the person in charge; therefore, it accepts the objective responsibility. Thus, it does not require the approval of the competent public agency. The adoption of compliance mechanisms generates the reduction, but not the exclusion, of the liability: it is an important factor to be considered in the administrative sanction dosimetry.

KEYwoRDs: Corporate responsibility - Objective responsibility - Double imputation - Compliance - Will. 
SumÁRIO: 1. Breve introdução. 2. Pessoa juridica: ficção ou realidade? 3. Pessoa jurídica e vontade. 4. Pessoa juridica e responsabilidade. 4.1. Responsabilidade subjetiva da pessoa juridica. 4.2. Responsabilidade objetiva da pessoa juridica. 5. Compliance e responsabilização da pessoa juridica. 6. Conclusões. 7. Referências bibliográficas.

\section{BREVE INTRODUÇãO}

O tema do compliance passou a ser discutido no Brasil com a edição da Lei Anticorrupção, Lei Federal 12.846/2013. No inciso VIII do artigo $7^{\circ}$, ela determinou que, dentre outros fatores, deve ser levada em conta para dosimetria das sanções nela estabelecidas "a existência de mecanismos e procedimentos internos de integridade, auditoria e incentivo à denúncia de irregularidades e a aplicação efetiva de códigos de ética e de conduta no âmbito da pessoa jurídica". O "programa de integridade" foi disciplinado nos artigos 41 e 42 do Decreto Federal 8.420/2015. Passou-se a utilizar, na doutrina brasileira, a palavra "compliance" para se referir a esse programa ${ }^{1}$. Não se pretende, neste estudo, examinar o próprio conceito de compliance, mas, sim, a relação conceitual entre ele e a responsabilização da pessoa jurídica por atos de corrupção. A proposta é aprofundar o estudo da problemática existente sobre a responsabilização da pessoa jurídica e, diante dessa problemática, examinar o papel da compliance.

\section{Pessoa JuRídica: ficção OU ReAlidade?}

Qualquer neófito dos estudos jurídicos sabe que existem dois tipos de pessoas: as naturais ou físicas e as jurídicas ou morais. A personalidade jurídica é um atributo jurídico consistente na qualidade de ser titular de direitos e obrigações, de ser sujeito de direito². É o Direito que atribui personalidade, e o faz não apenas às pessoas físicas, mas também às pessoas jurídicas, a um conjunto de pessoas ou de bens. A personificação é um processo técnico do Direito de separação patrimonial, pois o patrimônio desse conjunto fica segredado do patrimônio das pessoas físicas que o integram ${ }^{3}$. Muito se discute se as pessoas jurídicas são uma realidade ou uma ficção. Concorda-se com Pontes de Miranda: trata-se de uma "falsa questão", pois a "realidade" é um conceito do mundo fático e

1. Por todos: CASTRO, Rodrigo Pironti Aguirre de; ZILIOTTO, Mirela Miró. Compliance nas contratações públicas: exigência e critérios normativos. 1. reimpr. Belo Horizonte: Fórum, 2019. p. 20; PAULA, Marco Aurélio Borges de; CASTRO, Rodrigo Pironti Aguirre de (Coord.). Compliance, gestão de risco e combate à corrução. 2. reimpr. Belo Horizonte: Fórum, 2019; ZENKNER, Marcelo; CASTRO, Rodrigo Pironti Aguirre de (Coord.). Compliance no setor público. Belo Horizonte: Fórum, 2020. As duas últimas obras reúnem vários trabalhos, de diversos autores, que utilizam a palavra "compliance" para se referir aos mecanismos de integridade.

2. Por todos: GOMES, Orlando. Introdução ao direito civil. 18. ed. Rio de Janeiro: Forense, 2001. p. 141142; AMARAL, Francisco. Direito civil: introdução. Rio de Janeiro: Renovar, 2000. p. 213-214.

3. Cf. COELHO, Fábio Ulhoa. Curso de direito civil. São Paulo: Saraiva, 2003. v. 1, p. 230-232. 
imputação de sanções administrativas pela prática de atos de corrupção a pessoas jurídicas que implementaram efetivo programa de compliance é inconstitucional. In verbis:

"A pessoa jurídica que instala e incorpora políticas de integridade, dedicada à implementação de programas de prevenção a delitos e à apuração de qualquer ato suspeito, que demonstre seu compromisso real com ética e com transparência e, sobretudo, que envida esforços reais em punir atos de corrupção no seio corporativo pode ser imunizada de sanções decorrentes de atos ilícitos provocados por terceiros e que lhe são imputados, subsistindo tão somente o ônus de reparar os danos, arcar com os prejuízos e ver sustados ou anulados os benefícios que eventualmente obteve com o comportamento ilícito do qual não contribuiu ${ }^{50}$."

Não foi isso que estabeleceu a Lei Anticorrupção. Nos termos do inciso VIII de seu art. $7^{\circ}$, a adoção do compliance não afasta as sanções nela previstas, mas deve ser levada em consideração para sua dosimetria. Trata-se de uma típica atenuante ${ }^{51}$. Não se deve confundir a circunstância atenuante com a causa de diminuição de pena: só a última permite a fixação da sanção aquém do mínimo estabelecido pelo Legislador ${ }^{52}$. Por conseguinte, ainda que seja estabelecido um efetivo programa de compliance, presentes os três pressupostos fixados no item anterior, a pessoa jurídica responderá, ao menos, pela multa estabelecida no inciso I do art. $6^{\circ}$ da Lei Anticorrupção em seu patamar mínimo: 0,1\% do faturamento bruto do último exercício anterior à instauração do processo administrativo. É mister observar: mesmo um efetivo programa de compliance não levará necessariamente à fixação do mínimo. Isso porque as outras circunstâncias, discriminadas no art. $7^{\circ}$ da Lei Anticorrupção, poderão justificar a fixação acima do mínimo. Em suma: pela Lei, a adoção do compliance não é causa de exclusão da sanção, mas mera circunstância atenuante, que deve ser obrigatoriamente observada na fixação das sanções.

A opção do Legislador é inconstitucional? Sem desprestigiar o entendimento contrário, nada há de inconstitucional, no âmbito administrativo, na responsabilização objetiva da pessoa jurídica. A presunção gerada pela adoção do compliance de que os dirigentes da empresa não compactuam com o ato de corrupção praticado pelo preposto é relativa e não absoluta. Por óbvio, é plenamente possível que a pessoa jurídica implemente um denso e efetivo programa de integridade e, ainda assim, seus dirigentes, a portas fechadas, de modo camuflado, determinem a algum subordinado que pratique o ato. Adoção de compliance é um mecanismo minimizador da corrupção, mas não é, por óbvio, um mecanismo garantidor de sua inexistência. Além dessa presunção relativa, não é possível negar o fato de que a empresa é efetiva ou potencialmente beneficiária do ato. Logo, ainda que haja um denso programa implementado, praticado um ato de corrupção (típico,

50. SANTOS, Kleber Bispo dos. Acordo de leniència na Lei de improbidade administrativa e na Lei anticorrupção. Rio de Janeiro: Lumen Juris, 2018. p. 42.

51. É uma atenuante genérica expressamente delineada. Sobre o conceito, por todos: ESTEFAM, André; GONÇALVES, Victor Eduardo Rios. Op. cit., p. 608.

52. Cf. GOMES, Luiz Flávio; MOLINA, Antonio García-Pablos de. Op. cit., p. 742. 
antijurídico, culpável e punível) por uma pessoa física ligada à empresa, ato que objetivamente seja praticado no interesse ou em benefício dela, a pessoa jurídica dever ser responsabilizada administrativamente. A responsabilidade é objetiva e, por conseguinte, $o$ compliance tem o condão, apenas, de atenuar a sanção.

\section{CONClusõES}

1. Saber se as pessoas jurídicas são uma realidade ou uma ficção consiste numa falsa questão, pois é própria do mundo do ser e as pessoas jurídicas são uma realidade do mundo do Direito. A responsabilidade de uma pessoa jurídica é conceitualmente problemática, pois só quem possui vida anímica própria tem naturalmente vontade.

2. A vontade da pessoa jurídica é explicada pela teoria do órgão, que a torna presente nas relações jurídicas: a vontade do órgão é imputada à pessoa jurídica. Contudo, o órgão também não tem vida anímica própria, de modo que a vontade da pessoa física, que integra o órgão, é imputada a ele. Há, assim, duas relações de imputação: a vontade do agente é imputada ao órgão e a vontade do órgão é imputada à pessoa jurídica.

3. Em relação ao Estado, a atuação das pessoas físicas que estão no exercício de função pública é sempre imputada ao Estado; em relação às pessoas privadas essa imputação depende da chancela do órgão competente, nos termos da lei e do respectivo ato constitutivo. A vontade real da pessoa jurídica é expressa pela vontade ou da totalidade ou da maioria dos membros de seus órgãos colegiados e assentada em suas atas, relatórios legais; é, pois, uma vontade documentada.

4. Muito se discutiu no Brasil sobre a responsabilização subjetiva da pessoa jurídica. De início, oSTJ consagrou o entendimento de que a punição pressuporia a concomitante punição de seus dirigentes, o que ficou conhecido como "teoria da dupla imputação". O STF, porém, entendeu que as responsabilidades são autônomas. Ainda que não se exija a dupla responsabilização, exige-se: que tenha sido praticado um fato típico, antijurídico, culpável e punível por uma pessoa física; que o órgão deliberativo da entidade tenha autorizado a prática dessa conduta. Sem a primeira exigência, não há uma conduta punível; sem a segunda, não há culpa.

5. Não se admite no Direito brasileiro a responsabilização penal objetiva. A responsabilidade administrativa, ao contrário, admite a dissociação entre a figura do autor da infração e a do responsável. Aceita-se, por conseguinte, imposição de sanção administrativa a pessoa diversa do autor da infração. Por consequência, é perfeitamente possível a responsabilização administrativa objetiva.

6. A Lei Anticorrupção estabeleceu expressamente a responsabilidade objetiva da pessoa jurídica por atos de corrupção. Sem embargo, como a conduta da pessoa jurídica pressupõe a conduta de uma pessoa física, para a pessoa jurídica responder objetivamente por um ato de corrupção énecessário que uma pessoa física, a ela vinculada, tenha praticado um ato de corrupção típico, antijurídico, culpável e punível. Por ser objetiva, a responsabilização dispensa que a conduta tenha sido praticada pelo órgão competente para externar a vontade da pessoa jurídica; basta que haja um vínculo entre a pessoa física infratora e a pessoa jurídica. 
7. A adoção de mecanismo do compliance não é suficiente para afastar a responsabilização da pessoa jurídica por atos de corrupção praticados por pessoas físicas a ela vinculadas. A consequência jurídica da adoção do compliance não éa exclusão da responsabilidade, mas a diminuição da responsabilidade. É um relevante fator a ser considerado para a dosimetria da sanção administrativa.

\section{REFERÊNCIAS BIBLIOGRÁFICAS}

AMARAL, Francisco. Direito civil: introdução. Rio de Janeiro: Renovar, 2000.

BANDEIRA DE MELLO, Celso Antônio. Apontamentos sobre a teoria dos órgãos públicos. Revista de Direito Administrativo e Infraestrutura, São Paulo, ano 02, n. 04, p. 423-434, jan.-mar. 2018.

BANDEIRA DE MELLO, Celso Antônio. Curso de direito administrativo. 34. ed. São Paulo: Malheiros, 2019.

BITENCOURT, Cezar Roberto. Manual de direito penal. 6. ed. São Paulo: Saraiva, 2000. v. 1.

BORDALO, Rodrigo. Os órgãos colegiados no direito administrativo brasileiro. São Paulo: Saraiva, 2016.

CASTRO, Rodrigo Pironti Aguirre de; ZILIOTTO, Mirela Miró. Compliance nas contratações públicas: exigência e critérios normativos. 1. reimpr. Belo Horizonte: Fórum, 2019.

CAVALCANTI, Amaro. Responsabilidade civil do Estado. 2. ed. Rio de Janeiro: Borsoi, 1957. v. 1.

CHEVALLIER, Jacques. O Estado de direito. Trad. Antonio Araldo Ferraz Dal Pozzo e Augusto Neves Dal Pozzo. Belo Horizonte: Fórum, 2013.

COELHO, Fábio Ulhoa. Curso de direito civil. São Paulo: Saraiva, 2003. v. 1.

DALLARI, Dalmo de Abreu. Elementos de teoria geral do Estado. 33. ed., 5. tir. São Paulo: Saraiva, 2018.

DAL POZZO, Antonio Araldo Ferraz et al. Lei anticorrupção. São Paulo: Contracorrente, 2015.

ESTEFAM, André; GONÇALVES, Victor Eduardo Rios. Direito penal: parte geral. 8. ed. São Paulo: Saraiva, 2019.

FERRARA, Francisco. Teoria de las personas jurídicas. Trad. Eduardo Ovejero y Maury. Granada: Comares, 2006.

GOMES, Luiz Flávio; MOLINA, Antonio García-Pablos de. Direito penal: parte geral. São Paulo: Ed. RT, 2007. v. 2.

GOMES, Luiz Flávio; MOLINA, Antonio García-Pablos de; BIANCHINI, Alice. Direito penal. São Paulo: Ed. RT, 2007. v. 1.

GOMES, Orlando. Introdução ao direito civil. 18. ed. Rio de Janeiro: Forense, 2001.

GRECO FILHO, Vicente; ROSSI,João Daniel. O combate à corrupção e comentários

à lei de responsabilidade de pessoas jurídicas. São Paulo: Saraiva, 2015.

HEINEN, Juliano. Comentários à lei anticorrupção. Belo Horizonte: Fórum, 2015. 
MARTINS, Ricardo Marcondes. Efeitos dos vícios do ato administrativo. São Paulo: Malheiros, 2008.

MICHOUD, Léon. La théorie de la personnalité morale et son application au droit français. 2. ed. Paris: Librairie Générale de Droit \& de Jurisprudence, 1924. V. I.

MÜLLER, Friedrich. O novo paradigma do direito: introdução à teoria e metódica estruturantes do direito. Trad. Rossana Ingrid Jansen dos Santos et al. São Paulo: Ed. RT, 2007.

PAULA, Marco Aurélio Borges de; CASTRO, Rodrigo Pironti Aguirre de (Coord.). Compliance, gestão de risco e combate à corrução. 2. reimpr. Belo Horizonte: Fórum, 2019.

PONTES DE MIRANDA. Tratado de direito privado. 2. tir. São Paulo: Ed. RT, 2012. t. I.

PRADO, Luiz Regis. Responsabilidade penal da pessoa jurídica: fundamentos e implicações. In: PRADO, Luiz Regis; DOTTI, René Ariel (Coord.). Responsabilidade penal da pessoa jurídica: em defesa do princípio da imputação subjetiva. São Paulo: Ed. RT, 2013.

SANTOS, Juarez Cirino dos. Direito penal: parte geral. 8. ed. Florianópolis: Tirant lo Blanch, 2018.

SANTOS, Kleber Bispo dos. Acordo de leniência na Lei de improbidade administrativa e na Lei anticorrupção. Rio de Janeiro: Lumen Juris, 2018.

SEVERO, Sérgio. Tratado da responsabilidade pública. São Paulo: Saraiva, 2009.

TAVARES, Juarez. Fundamentos de teoria do delito. Florianópolis: Tirant lo Blanch, 2018.

TEOTÔNIO, Luís Augusto Freire. Culpabilidade. Campinas: Minelli, 2002.

ZAFFARONI, Eugenio Raúl. Parecer a Nilo Batista sobre a responsabilidade penal das pessoas jurídicas. In: PRADO, Luiz Regis; DOTTI, René Ariel (Coord.). Responsabilidade penal da pessoa jurídica: em defesa do princípio da imputação subjetiva. São Paulo: Ed. RT, 2013.

ZENKNER, Marcelo; CASTRO, Rodrigo Pironti Aguirre de (Coord.). Compliance no setor público. Belo Horizonte: Fórum, 2020. 


\section{PESQUisas do EDITORIAL}

\section{Veja também Doutrinas relacionadas ao tema}

- Compliance e responsabilidade penal ambiental da pessoa juridica no século XXI, de Andréia Leal Ferro - RBCCrim 160/19-55 (DTR|2019|40000);

- Direito penal econômico, criminal compliance e seus possíveis impactos nos preceitos de responsabilização penal da pessoa juridica, de Carolina Alencar Marchesano - RDPec 2/13-36 (DTR|2020|7585); e

- 0 ônus da prova da existência e eficácia dos programas de compliance no âmbito do processo penal das pessoas jurídicas: um estudo com base no ordenamento jurídico espanhol, de Túlio Felippe Xavier Januário - RBCCrim 160/219-257 (DTR|2019|40703). 


\section{SUMÁRIO}

LINHA EDITORIAL - EDITORIAL LINE

APRESENTAÇÃO - INTRODUCTION

1. Seção - Direito Administrativo

Section 1 - Administrative LaW

A) Princíplos do Direito Administrativo

A) Principles of Administrative Law

Precedentes administrativos: um caminho para segurança jurídica nas relações entre a Administração Pública e os cidadãos

Administrative precedents: a path to legal security in the relationship between public administration and citizens

Carlos Henrique Benedito Nitão loureiro e Vladimir da Rocha França.....

Ética da discussão e princípios da administração pública: o administrador público mentiroso e a improbidade administrativa Discussion ethics and principles of public administration: the lying public administrator and administrative improbity

Caroline Müller Bitencourt e Janriê Rodrigues Reck.

B) Processo Administrativo

B) Administrative Proceedings

Consensualidade como modo alternativo de exercício da pretensão punitiva estatal no processo administrativo sancionador

Consensuality as an alternative mode for the exercise of state punitive pretension in the administrative sanctional process

Shirlei Silmara de Freitas Mello e Daniela Almeida Campos. 


\section{C) Licitação e Contratos Administrativos \\ C) Bidding and Administrative Contracts}

A consagração popular no procedimento de inexigibilidade para contratação de artistas musicais

The popular consecration in the inexigibility procedure for contracting musical artists

Pedro Henrique Maciel Barros e Marina Zava de Faria

D) Intervenção do Estado na Ordem Social

D) State Intervention in the Social Order

Defensoria Pública e legitimação social do direito: uma análise sobre reconhecimento e paridade participativa na tutela de grupos vulneráveis

Public Defender's office and social legitimation: an analysis on recognition and participative parity in the protection of vulnerable groups

Cristian Patric de Sousa Santos e Ricardo Maurício Freire Soares

\section{SeÇão - Complance}

\section{Section 2 - Compliance}

Compliance e responsabilidade de pessoas jurídicas

Compliance and responsibility of legal entities

Ricardo Marcondes Martins

Compliance ambiental-energético e a ecoeficiência empresarial: cenário na pandemia da Covid-19

Environmental-energy compliance and business eco-efficiency: pandemic scenario of Covid-19

Priscila Elise Alves Vasconcelos, Cleyson de Moraes Mello e Paulo Sérgio

VASCONCELOS

\section{SeÇÃo - Doutrina Estrangeira}

\section{SECTION 3 - FOREIGN DOCTRINE}

Sobre la naturaleza jurídica de los aeropuertos privados internacionales

The legal nature of international private airports

Jaime Rodriguez-Arana Muñoz 
La libre competencia en la compra pública

Free competition in public procurement

Juan David Duque Botero.

El procedimiento sancionadoren la Ley General de Responsabilidades Administrativas

The sanctioning procedure in the General Administrative Responsibilities Act

Manlio Fabio Casarin León.

\section{4a. SeÇão - Pareceres}

\section{Section 4 - Legal Opinions}

Controle do ato discricionário arbitrário na gradação da pena administrativa de multa aplicada pela administração pública federal, atecnia do caput do art. $2^{\circ}$ e inobservância da primariedade do inciso I, da Lei 7.889/1989: desrespeitos aos princípios da motivação, proporcionalidade, razoabilidade e direitos fundamentais da empresa/administrada que pode inviabilizar atividade econômica de empresa de economia familiar protegida pelo artigo 170 da Constituição de 1988

Control of the arbitrary discretionary act in grading the fine administrative penalty applied by the federal public administration, atecnia of the caput of art. 2nd and inobservance of the primariety of item I, of Law 7,889/1989: disrespect to the principles of motivation, proportionality, reasonability and fundamental rights of the company/manager that may invibialize the economic activity of the family economy company protected by article 170 of the 1988 Constitution

Jerson Carneiro Gonçalves Junior

\section{SeÇÃo - ComentÁrios À JURISPRUdÊnCIA \\ SECTION 5 - CommentS of JuRISPRUdENCE}

ADI 6.427 DF: inovação normativa pelo Judiciário na interpretação conforme a Constituição

ADI 6,427 DF: normative innovation by the Judiciary in the interpretation according to the Constitution

Adilson Neri Pereira 
Acórdão 169/2021-TCU: um novo entendimento jurisprudencial para o cálculo da garantia adicional em contratos administrativos Judgment 169/2021-TCU: a new jurisprudential understanding for the calculation of the additional guarantee in administrative contracts

Augusto César Tavares de Lira da Cunha e Pedro Flávio Cardoso lucena .... 301

\section{SeÇÃo - EntreVISTA}

\section{Section 6 - InTERVIEW}

Entrevista com Dalmo de Abreu Dallari Interview with Dalmo de Abreu Dallari

Augusto Neves Dal Pozzo e Ricardo Marcondes Martins.

\section{Seção - Memória do Direito Administrativo}

\section{Section 7 - Retrospective of Administrative Law}

0 Conselho de Estado e o contencioso administrativo no Brasil The Council of State and administrative litigation in Brazil

Modalidades de descentralização administrativa e seu controle Modalities for administrative decentralization and its control

Celso Antônio Bandeira de Mello.

Impossibilidade de o INPS multar municípios Impossibility for the Brazilian Institute of Social Welfare to fine municipalities

Celso Antônio Bandeira de Mello.

A personalidade do Estado

The personality of the State

Oswaldo Aranha Bandeira de Mello.

Normas de Publicação para Autores de Colaboração Autoral Inédita ..... 393

Publication Guidelines for Authors to Submit Unpublished Articles ...... 395 




\section{NESTA EDIÇÃO:}

\section{ÉTICA DA DISCUSSÃO E PRINCÍPIOS DA ADMINISTRAÇÃO PÚBLICA: O ADMINISTRADOR PÚBLICO MENTIROSO E A IMPROBIDADE ADMINISTRATIVA}

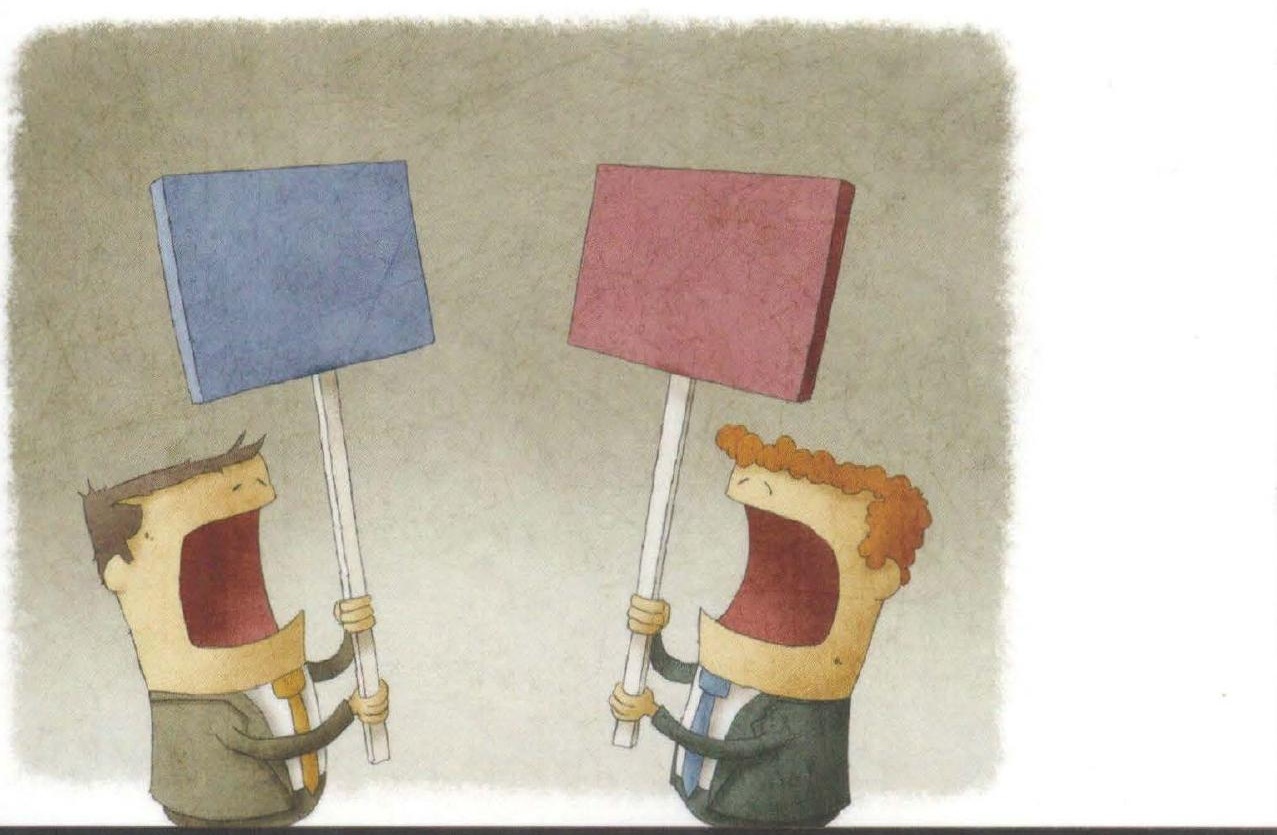

REVISTA DE DIREITO ADMINISTRATIVO, INFRAESTRUTURA, REGULAÇÃO E COMPLIANCE
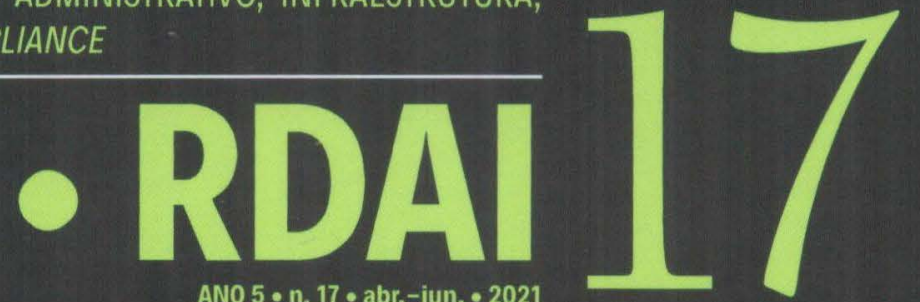

Journal of Administrative Law, Infrastructure, Regulation and Compliance

N. 5 • ISSUE $17 \cdot$ April - June $\cdot 2021$

COORDENACẢO

AUGUSTO NEVES DAL POZZO E RICARDO MARCONDES MARTINS 